\title{
AVALIAÇÃO DA EFICIÊNCIA DE AGENTES COAGULANTES EM EFLUENTE DE FRIGORÍFICO
}

\section{EVALUATION OF COAGULANT AGENTS EFFICIENCY IN REFRIGERATION WASTE}

\author{
Alexandre Teixeira Souza, Danielli Chagas \\ Universidade do Oeste Paulista - UNOESTE, Presidente Prudente, SP. \\ E-mail: alteiso@hotmail.com; daniellichagas1@gmail.com
}

RESUMO - Nas indústrias frigoríficas são utilizadas grandes quantidade de água durante todo o processo, gerando um efluente que precisa de tratamento antes do seu lançamento. A proposta do trabalho foi realizar um estudo comparativo de três coagulantes utilizados no tratamento de efluentes: Policloreto de Alumínio (PAC), Sulfato de Alumínio $\left(\mathrm{Al}_{2}\left(\mathrm{SO}_{4}\right)_{3}\right)$ e o Tanino Vegetal, com o auxílio de um floculante: Polímero o Aniônico, analisando a eficiência de remoção de DQO e turbidez. Foram conduzidos os ensaios de coagulação/floculação em jarro (jar test) para a otimização da concentração dos coagulantes. Constatou-se que o coagulante natural apresentou uma pequena variação no parâmetro $\mathrm{pH}$, evitando o uso de produto químicos para a sua correção. Os resultados dos percentuais de remoção de turbidez indicaram um grande potencial para o Tanino quando comparado aos dois coagulantes químicos.

Palavras-chave: Tanino; Coagulação / floculação; Efluentes.

\begin{abstract}
In the refrigeration industry, a large amount of water is used throughout processes, generating effluents that need treatment before release. The purpose of this work was to make a comparative study of three coagulants used in the treatment of effluents: Aluminum Polychloride (PAC), Aluminum Sulphate $\left(\mathrm{Al}_{2}\left(\mathrm{SO}_{4}\right)_{3}\right)$ and Vegetable Tannin, with the aid of a flocculant (Anionic Polymer) by analyzing COD removal efficiency and turbidity. Jar coagulation / flocculation tests were conducted to optimize the concentration of coagulants. It was found that the natural coagulant presented a small variation in the $\mathrm{pH}$ parameter, avoiding the use of chemicals for its correction. The results of turbidity removal percentages indicated a great potential for Tannin when compared to the other chemical coagulants.

Keywords: Tannin; Coagulation/flocculation; Effluents.
\end{abstract}




\section{INTRODUÇÃO}

São efluentes das indústrias frigoríficas concentrações de óleos e graxas, sulfatos, nitratos e fosfatos e como consequência, possuem alta DQO e DBO. Apresenta ainda, sólidos em suspensão, material flotável, baixa biodegradabilidade, temperaturas elevadas. (VIDAL, 2000; JUNG et al., 2002; NAIME, GARCIA, 2005). Decorrente a essas características, esses efluentes tendem a sofrer rápida degradação, causando odor, além de apresentar um alto potencial de contaminação do solo e das águas superficiais e subterrâneas se lançado sem o tratamento adequado no meio ambiente (WERBERICH, 2017).

Como previsto do Art. 3ㅇ da Resolução CONAMA N 430 DE 2011, os efluentes de qualquer fonte poluidora precisam passar por um tratamento, antes do seu lançamento direto no corpo receptor, que atendam os padrões previstos nesta Resolução ou em outras normas aplicáveis (BRASIL, 2011).

Os tratamentos dos efluentes industriais devem seguir à legislação ambiental. $O$ tratamento consiste na transformação dos poluentes dissolvidos e em suspensão em gases inertes e ou sólidos sedimentáveis para, nas próximas etapas, ocorrer a separação das fases sólida e líquida (BRANCO; ZORZIN, 2016).

Devido a constante necessidade de tratamentos de baixo custo, acessível e que não demandam de grandes áreas, o tratamento físico-químico em efluente de abatedouro pode ser utilizado como prétratamento, utilizando coagulantes alternativos, sendo tratamento viável de redução da matéria orgânica para posteriormente passar pelo tratamento biológico, ou em alguns casos substituir o processo biológico (WERBERICH, 2017).

O tratamento físico-químico consiste na coagulação seguida da floculação e sedimentação. $\mathrm{Na}$ coagulação ocorre a desestabilização dos coloides, decorrente da adição de agentes coagulantes, diminuindo a repulsão elétrica entre as partículas que passam a formar aglomerados. Na fase de floculação esses aglomerados se unem, formando então os flocos, que sedimentam, devido à força da gravidade (ORSSATTO et al., 2018).

Os coagulantes podem ser de origem orgânica ou inorgânica, dentre os inorgânicos, os mais utilizados são: sulfato de alumínio, policloreto de alumínio (PAC) e cloreto férrico. Entre os orgânicos estão os a base de taninos e poliamidas. Sob o ponto de vista econômico, geralmente, são mais utilizados os inorgânicos, por apresentarem alta eficiência e baixo custo. Já sob a ótica ambiental, os mais adequados são os orgânicos, já que em seu lodo gerado não carreiam resquícios de sais de ferro e alumínio (ROSA, 2019).

Os coagulantes inorgânicos estão, cada vez mais, sendo substituídos por produtos de origem orgânica, devido à demasiada preocupação com os recursos naturais e aos rigorosos padrões estabelecidos pelas legislações ambientais.

Apesar da comprovada eficiência do tratamento dos coagulantes inorgânicos e orgânicos sintéticos, as desvantagens associadas motivaram a busca por coagulantes naturais que geralmente são mais amigáveis ao meio ambiente em termos de uso e produção. As principais vantagens atraentes dos coagulantes naturais estão em sua renovabilidade (matéria-prima pode ser obtida facilmente), biodegradabilidade, não toxicidade e relação custo-efetividade (manuseio de lodo e custo de coagulante) (SALEEM; BACHMANN, 2019a).

Os coagulantes naturais podem ser obtidos por uma variedade de fontes naturais, como plantas, sementes, crustáceos marinhos e biomassa de moluscos (camarões e caranguejos) e organismos microbianos, com a maioria da pesquisa focada no coagulante natural a base de plantas e biomassa marinha (WEl et al., 2018).

O mecanismo de coagulação predominante dos coagulantes naturais difere dos coagulantes inorgânicos e 
orgânicos sintéticos, pois os coagulantes naturais não formam precipitados de hidróxido na água. Em vez disso, devido às estruturas poliméricas dos coagulantes naturais com grupos funcionais carregados, a neutralização e a ponte de carga são os dois mecanismos dominantes para a formação de flocos e remoção de impurezas (SALEEM; BACHMANN, 2019a).

Vários trabalhos comprovam a eficácia de coagulantes naturais (principalmente quitosana e coagulantes à base de plantas) em várias aplicações de tratamento de água e efluentes (CHOY et al., 2015, 2014; MOHD-SALLEH et al., 2019; OLADOJA, 2015; SALEEM; BACHMANN, 2019b; VILLASEÑOR-BASULTO et al., 2018; YIN, 2010).

Neste contexto, o presente trabalho tem por objetivo avaliar o desempenho dos coagulantes, natural Tanfloc SG em comparação com os metálicos, PAC e sulfato de alumínio, no processo de coagulação/floculação para o tratamento de efluente industrial do frigorífico em questão.

\section{MATERIAIS E MÉTODOS}

Os ensaios de coagulação/floculação foram realizados com três coagulantes, sendo eles: Tanino, Policloreto de Alumínio (PAC), Sulfato de Alumínio $\left(\mathrm{Al}_{2}\left(\mathrm{SO}_{4}\right)_{3}\right)$ (Figura 1) e um Polímero Aniônico.

Figura 1. Coagulantes: Tanino, Policloreto de Alumínio e Sulfato de Alumínio.

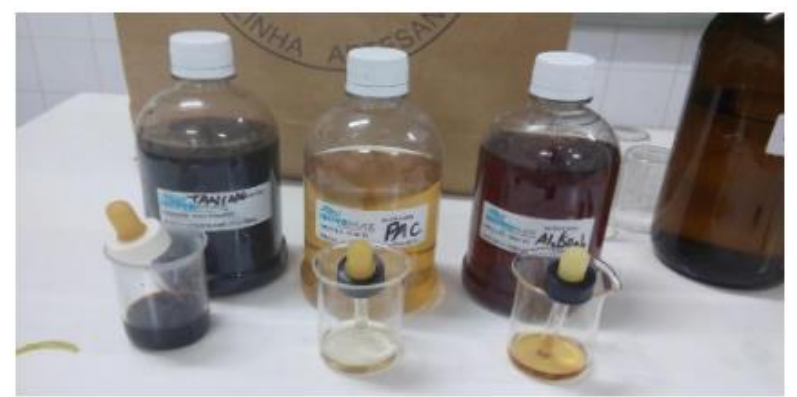

Fonte: Os autores.

A parte experimental desta pesquisa foi realizada no Laboratório de Águas da Universidade do Oeste Paulista (UNOESTE), onde foram conduzidos os ensaios de coagulação/floculação e alguns parâmetros específicos necessários para se avaliar a eficiência dos tratamentos a fim de constar qual o mais adequado para aplicação em grande escala no frigorífico.

\subsection{Ensaios preliminares}

Foram realizados ensaios preliminares em proveta, utilizando $100 \mathrm{ml}$ do efluente com adição de todos os coagulantes para encontrar uma faixa ótima de coagulação (Figura 2).

Figura 2. Teste em proveta para os coagulantes: Tanino, Policloreto de Alumínio e Sulfato de Alumínio.

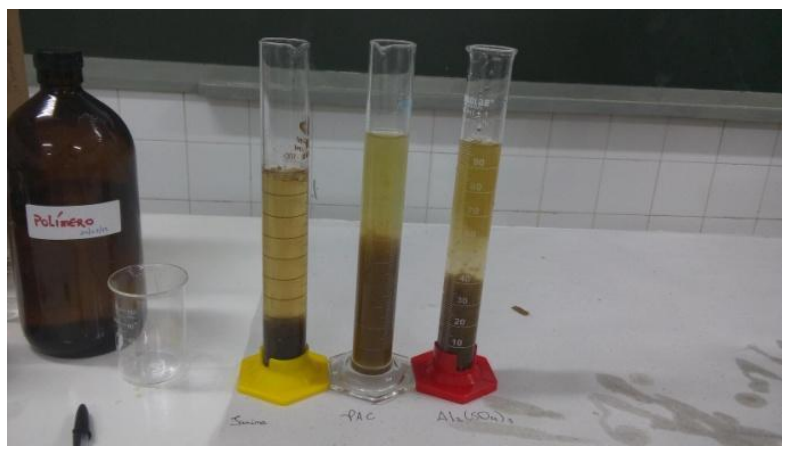

Fonte: Os autores.

Com os resultados otimizados dos ensaios em proveta $(100 \mathrm{~mL})$, determinou-se a quantidade de coagulantes necessários para cada jarro (1.000 mL), variando a concentração para obter uma concentração ótima.

\subsection{Processo de coagulação}

Os ensaios de coagulação/floculação foram realizados em Jar-Test. Na realização dos ensaios foram utilizados 5 jarros (1 Litro para cada jarro). Após adicionadas as concentrações pré-determinadas, nos ensaios preliminares, do coagulante e do polímero em cada jarro, houve a homogeneização a $120 \mathrm{rpm}$ por 2 min., 20 rpm por 5 min. e 5 min. para decantação do material floculado ao fim do processo.

O objetivo da utilização do Jar-Test nos ensaios foi simular, em escala de laboratório, as condições físicas de precipitação química que mais se aproxime da realidade da empresa. 


\subsection{Determinações analíticas}

As determinações analíticas foram realizadas, segundo o Standard Methods conforme mostra a Tabela 1, com o objetivo de fazer o comparativo entre as amostras e constar qual coagulante obteve melhores resultados.

Tabela 1. Parâmetros investigados e metodologia utilizada durante os experimentos.

\begin{tabular}{|c|c|c|}
\hline PARÂMETRO & MÉTODO & REFERÊNCIA \\
\hline DQO & $\begin{array}{l}\text { Refluxo } \\
\text { Fechado }\end{array}$ & $\begin{array}{c}\text { SMWW, 21ạ } \\
\text { Edição, Método } \\
5220\end{array}$ \\
\hline Turbidez & Nefelométrico & $\begin{array}{c}\text { SMWW, 21ạ } \\
\text { Edição, Método } \\
2130-B\end{array}$ \\
\hline $\mathrm{pH}$ & Potenciométrico & $\begin{array}{c}\text { SMWW, 21ạ } \\
\text { Edição, Método } \\
4500-\mathrm{H}+2\end{array}$ \\
\hline
\end{tabular}

Fonte: Os autores.

Foram realizadas as análises apenas com as amostras consideradas ótimas, de cada ensaio, e com uma amostra do efluente bruto totalizando 4 análises para os parâmetros de $\mathrm{pH}$ e DQO, já para a Turbidez foi realizada a leitura para todos os jarros e uma amostra do efluente bruto, totalizando 6 análises por coagulante.

Foi calculado o teor de remoção da turbidez, sólidos em suspensão, utilizando a leitura de turbidez do efluente bruto $\left(T_{i}\right)$ e tratado $\left(T_{f}\right)$ com a fórmula de eficiência, verificando assim qual concentração apresentou melhor resultado.

Onde:

$$
E=\frac{T i-T f}{T i} \times 100
$$

$\mathrm{E}=$ eficiência do tratamento (\%);

$\mathrm{T}_{\mathrm{i}}=$ turbidez inicial (NTU);

$\mathrm{T}_{\mathrm{f}}=$ turbidez final (NTU).

Para a DQO também foi calculado o seu teor de eficiência, através da fórmula:

$$
E=\frac{D Q O i-D Q O f}{D Q O i} \times 100
$$

Onde:

$\mathrm{E}=$ eficiência do tratamento (\%);

$\mathrm{DQO}_{\mathrm{i}}=\mathrm{DQO}$ inicial $\left(\mathrm{mg} . \mathrm{L}^{-1} \mathrm{O}_{2}\right)$;

$\mathrm{DQO}_{\mathrm{f}}=\mathrm{DQO}$ final $\left(\mathrm{mg} . \mathrm{L}^{-1} \mathrm{O}_{2}\right)$.

\section{RESULTADOS E DISCUSSÃO}

\subsection{Ensaios preliminares}

Foram realizados os ensaios preliminares com o objetivo de identificar uma condição inicial (análise qualitativa), encontrou-se a faixa ótima de coagulação para o PAC com 2 gotas de PAC e 3 gotas do polímero, para o Tanino com 16 gotas do polímero e 16 gotas do tanino, para o sulfato de alumínio com 2 gotas do sulfato e 2 gotas do polímero. Posteriormente utilizaram-se os parâmetros: concentração dos coagulantes (Tabela 2), tempo de agitação e tempo de decantação.

\begin{tabular}{|c|c|c|c|c|c|c|}
\hline \multirow{3}{*}{$\begin{array}{c}\text { ENSAIOS } \\
\text { JARROS } \\
\text { Quant. }\end{array}$} & \multicolumn{6}{|c|}{ COAGULANTES } \\
\hline & \multicolumn{2}{|c|}{ PAC } & \multicolumn{2}{|c|}{ TANINO } & \multicolumn{2}{|c|}{ SULFATO DE ALUMÍNIO } \\
\hline & $\begin{array}{c}\text { Coagulante } \\
\text { (gotas/L) }\end{array}$ & $\begin{array}{l}\text { Polímero } \\
\text { (gotas/L) }\end{array}$ & $\begin{array}{c}\text { Coagulante } \\
\text { (gotas/L) }\end{array}$ & $\begin{array}{l}\text { Polímero } \\
\text { (gotas/L) }\end{array}$ & $\begin{array}{c}\text { Coagulante } \\
\text { (gotas/L) }\end{array}$ & $\begin{array}{l}\text { Polímero } \\
\text { (gotas/L) }\end{array}$ \\
\hline Jarro 1 & 26 & 36 & 80 & 80 & 20 & 20 \\
\hline Jarro 2 & 28 & 38 & 90 & 90 & 40 & 40 \\
\hline Jarro 3 & 30 & 40 & 100 & 100 & 60 & 60 \\
\hline Jarro 4 & 32 & 42 & 110 & 110 & 80 & 80 \\
\hline Jarro 5 & 34 & 44 & 120 & 120 & 100 & 100 \\
\hline
\end{tabular}

Tabela 2. Concentrações utilizadas para o tratamento com os coagulantes.

Fonte: Os autores.

Pode-se observar que as concentrações que foram utilizadas para a realização dos ensaios mudavam de acordo com o coagulante, sendo o Tanino o que apresentou maior concentração (de 80 a 120 gotas/L), utilizando assim uma quantidade maior do produto, já a concentração utilizada para o Policloreto de Alumínio foi a menor 
(de 26 a 34 gotas/L), precisando assim de uma quantidade menor do coagulante, quando comparado aos outros.

As concentrações do Polímero também se alternaram de acordo com o coagulante, sendo iguais, as concentrações dos coagulantes e do Polímero, para o Tanino e o Sulfato de Alumínio, já para o PAC a quantidade requerida do Polímero foi maior do que a do coagulante.

\subsection{Processo de coagulação}

Coagulantes utilizados:

- Policloreto de Alumínio (PAC): MAX 18 (Inovamax)

- Sulfato de Alumínio: MAX 14 (Inovamax)

- Tanino: MAX ORGANIC (Inovamax)

Auxiliar de coagulação:

- Polímero: 0,1 g/L

\subsubsection{Sulfato de Alumínio + Polímero}

A Figura 3 apresenta o resultado obtido no Ensaio em Jar test utilizando Sulfato de Alumínio + Polímero com as seguintes dosagens: Sulfato de Alumínio: Faixa de 20 a 100 gotas/L; Polímero: Faixa de 20 a 100 gotas/L.

Figura 3. Ensaio na linha verde no Jar-test utilizando Sulfato de Alumínio + Polímero.

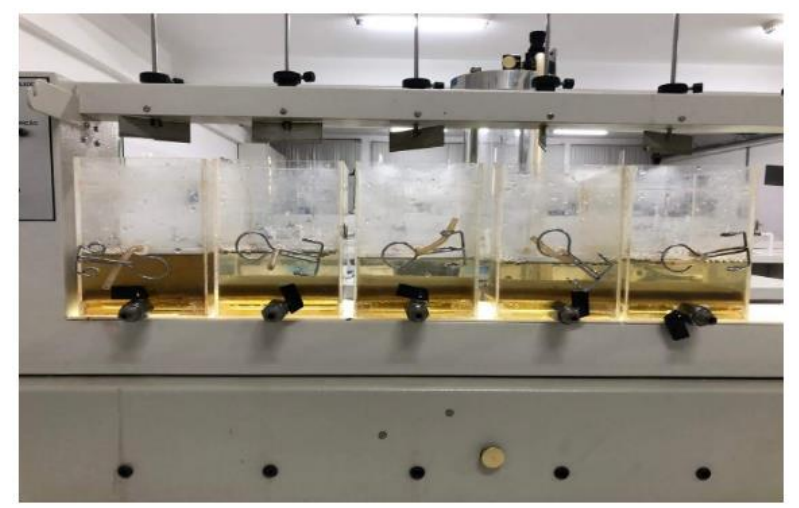

Fonte: Os autores.

Através da análise visual observa-se que o jarro 1 foi o que obteve menor clarificação e consequentemente menor remoção de turbidez e matéria orgânica. Já os outros jarros não apresentam muita diferença, necessitando de análises para classificar qual obteve melhores resultados, sendo considerada a amostra ótima.

De acordo com os ensaios realizados em laboratório, verificou-se que a dosagem ótima foi no jarro 3 (Sulfato de Alumínio: 60 gotas / Polímero: 60 gotas).

\subsubsection{Tanino Vegetal + Polímero}

A Figura 4 apresenta o resultado obtido no Ensaio na linha verde no Jar-Test utilizando Tanino + Polímero com as seguintes dosagens: Tanino: Faixa de 80 a 120 gotas/ L; Polímero: Faixa de 80 a 120 gotas/L.

Figura 4. Ensaio na linha verde no Jar-Test utilizando Tanino + Polímero.

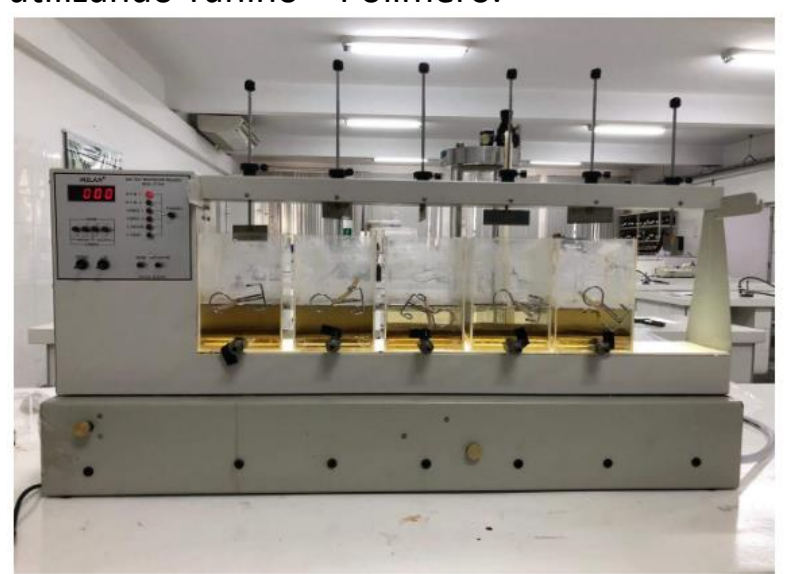

Fonte: Os autores.

Visualmente pode-se observar que os jarros que apresentaram melhor clarificação e maior massa precipitada foram os jarros $3 \mathrm{e}$ 4, para confirmar qual é amostra considerada ótima foram realizados análises em laboratório e verificou-se que a dosagem ótima foi no jarro 4 (Tanino: 110 gotas / Polímero: 110 gotas).

\subsubsection{Policloreto de Alumínio + Polímero}

A Figura 5 apresenta o resultado obtido no Ensaio na linha verde no Jar-Test utilizando Policloreto de Alumínio + Polímero com as seguintes dosagens: Policloreto de Alumínio: Faixa de 26 a 34 gotas/L; Polímero: Faixa de 36 a 44 gotas/L. 
Figura 5. Ensaio na linha verde no Jar-Test utilizando Policloreto de Alumínio + Polímero.

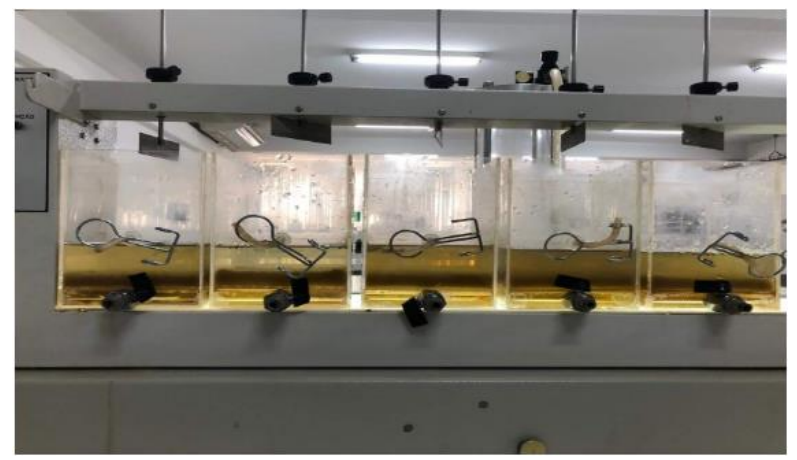

Fonte: Os autores.

Através de uma análise visual pode-se observar que as amostras não apresentam muita diferença entre si, com exceção do jarro 2 que se destaca por apresentar maior clarificação, possuindo resultados semelhantes em relação a clarificação.

De acordo com os ensaios realizados em laboratório, verificou-se que a dosagem ótima foi no jarro 2 (Policloreto de Alumínio: 28 gotas / Polímero: 38 gotas), como observado inicialmente através de análise visual.

\subsection{Determinações Analíticas}

Após os ensaios em Jar-Test foram realizados os testes de turbidez, sendo que na Tabela 3 estão apresentados os valores percentuais da remoção de turbidez com a utilização dos coagulantes escolhidos.

Tabela 03. Análise de eficiência de remoção de turbidez

\begin{tabular}{c|c|c|c|c|c|c|c|c|c}
\hline \multirow{2}{*}{ Amostra } & \multicolumn{4}{c|}{ PAC } & \multicolumn{3}{c|}{ TANINO } & \multicolumn{3}{c}{ SULFATO DE ALUMÍNIO } \\
\cline { 2 - 10 } & $\begin{array}{c}\text { Turbidez } \\
\text { (NTU) }\end{array}$ & $\begin{array}{c}\text { Desvio } \\
\text { Padrão }\end{array}$ & $\begin{array}{c}\text { Eficiência } \\
(\%)\end{array}$ & $\begin{array}{c}\text { Turbidez } \\
(\mathrm{NTU})\end{array}$ & $\begin{array}{c}\text { Desvio } \\
\text { Padrão }\end{array}$ & $\begin{array}{c}\text { Eficiência } \\
(\%)\end{array}$ & $\begin{array}{c}\text { Turbidez } \\
\text { (NTU) }\end{array}$ & $\begin{array}{c}\text { Desvio } \\
\text { Padrão }\end{array}$ & $\begin{array}{c}\text { Eficiência } \\
(\%)\end{array}$ \\
\hline $\begin{array}{c}\text { Efluente } \\
\text { bruto }\end{array}$ & 521 & \pm 6 & - & 521 & \pm 6 & - & 521 & \pm 6 & - \\
\hline Jarro 1 & 23,30 & $\pm 1,15$ & 95,50 & 56,50 & $\pm 1,77$ & 89,15 & 64,10 & $\pm 2,14$ & 87,70 \\
\hline Jarro 2 & 07,99 & $\pm 0,72$ & 98,46 & 43,90 & $\pm 0,28$ & 91,57 & 05,76 & $\pm 0,36$ & 98,90 \\
\hline Jarro 3 & 44,10 & $\pm 2,83$ & 91,53 & 01,53 & $\pm 0,24$ & 99,71 & 04,11 & $\pm 0,25$ & 99,21 \\
\hline Jarro 4 & 55,70 & $\pm 1,98$ & 89,31 & 01,29 & $\pm 0,16$ & 99,75 & 05,69 & $\pm 0,17$ & 98,91 \\
\hline Jarro 5 & 39,00 & $\pm 3,18$ & 92,51 & 33,20 & $\pm 1,84$ & 93,62 & 12,80 & $\pm 0,78$ & 97,54 \\
\hline
\end{tabular}

Fonte: Os Autores.

Pode-se observar que todos os coagulantes obtiveram altas eficiências de remoção de turbidez, sendo a menor de $87,70 \%$ referente ao jarro 1 do ensaio realizado com o Sulfato de Alumínio.

O Tanino apresentou uma maior eficiência $(99,75 \%)$ no Jarro 4 , sendo a maior de todas as análises realizadas com os três coagulantes, em que a concentração está representada na Tabela 2.

A melhor eficiência de remoção de turbidez para o PAC foi a obtida na amostra do jarro 2 com a remoção de sólidos em suspensão de 98,46\%, em que a concentração está representada na Tabela 2.

Dos testes realizados com o sulfato de alumínio o que apresentou melhor eficiência de remoção de turbidez $(99,21 \%)$ (Tabela 3$)$, foi o jarro 3 com a concentração apresentada na Tabela 2, os outros jarros apresentaram resultados similares, com exceção do jarro 1 que apresentou $87,70 \%$ de remoção.

Werberich (2017) obteve uma remoção de turbidez, em efluente frigorífico suíno, de $97,87 \%$ para o Tanino e $93,44 \%$ para o Sulfato de Alumínio. Gomes (2010), 
para efluente de frigorífico bovino, obteve $98,14 \%$ de remoção de turbidez com o coagulante PAC.

Os resultados obtidos no experimento, quando comparado com os casos presentes na literatura, encontram-se superiores, indicando eficiência por partes destes coagulantes em remoção de turbidez de efluentes industriais.

Para as amostras consideradas ótimas de cada coagulante e, ou seja, com uma maior remoção de turbidez, uma amostra do efluente bruto foi analisado o pH e a demanda química de oxigênio (DQO) e a sua eficiência, representado na Tabela 4.

Tabela 04. Valores de DQO, pH e porcentagem de remoção de DQO para as amostras ótimas

\begin{tabular}{c|c|c|c|c|c}
\hline AMOSTRA & $\begin{array}{c}\text { DQO } \\
\left(\mathbf{m g} \mathbf{~ L}^{-1} \mathbf{~ O}_{\mathbf{2}}\right)\end{array}$ & $\begin{array}{c}\text { Desvio } \\
\text { Padrão }\end{array}$ & $\begin{array}{c}\text { \% Eficiência } \\
\text { de remoção } \\
\text { de DQO }\end{array}$ & pH & $\begin{array}{c}\text { Desvio } \\
\text { Padrão }\end{array}$ \\
\hline Efluente bruto & 2853,33 & $\pm 9,43$ & - & 6,40 & $\pm 0,01$ \\
\hline PAC & 608,60 & $\pm 2,69$ & 78,76 & 5,57 & $\pm 0,01$ \\
\hline Tanino & 692,00 & $\pm 3,56$ & 75,74 & 6,12 & $\pm 0,01$ \\
\hline Sulfato de alumínio & 555,33 & $\pm 4,25$ & 80,53 & 4,12 & $\pm 0,01$ \\
\hline
\end{tabular}

Fonte: OsAutores.

Pode-se verificar que o sulfato de alumínio teve uma maior eficiência na remoção de matéria orgânica (80,53 \%) quando comparada com as outras amostras, sendo o Tanino o que apresentou menor eficiência (75,74 \%).

Rodrigues (2016), em seu tratamento de efluente de frigorífico suíno, obteve eficiência de $77,56 \%$ para PAC, $78,89 \%$ para o Sulfato de Alumínio e $67,78 \%$ para o Tanino. Ferrari (2015) obteve $67,70 \%$ de eficiência do Tanino, no tratamento de efluente frigorífico suíno, na remoção de DQO. Gomes (2010) no tratamento de efluente de frigorífico bovino obteve 95,44 \% de eficiência do PAC, na DQO. Costa (2016) obteve $72.61 \%$ de eficiência, em efluente de frigorífico avícola, com o coagulante Sulfato de Alumínio.

Analisando os resultados obtidos no experimento, pode-se observar que esses se encontram próximos e até mesmo superiores aos valores descritos em literatura.

Quando comparado os resultados de eficiência de remoção de turbidez e DQO pode-se observar que a turbidez não é proporcional a DQO, pois a amostra que obteve maior eficiência de turbidez foi o jarro 4 (Tabela 3) do ensaio do Tanino, já o que obteve melhor eficiência de DQO foi a amostra ótima do sulfato de Alumínio (Tabela 4).

Segundo a Resolução CONAMA $N^{\circ}$ 430 de 2011, que institui os padrões de lançamento para efluentes, o pH do efluente antes do seu lançamento deve estar na faixa entre 5 e 9 (BRASIL, 2011), observando os resultados da Tabela 4 referente às análises de $\mathrm{pH}$ pode-se constar que a amostra que apresentou maior variação de $\mathrm{pH}$ foi a do sulfato de alumínio $(4,12)$ saindo fora do parâmetros instituído pela resolução, desta maneira não sendo próprio para a utilização no tratamento.

A amostra que apresentou menor variação de $\mathrm{pH}(6,12)$ foi a referente ao Tanino, a amostra do PAC apresentou um pH de 5,57, sendo assim, $\mathrm{O} \mathrm{pH}$ dos dois coagulantes no efluente se enquadraram dentro dos padrões de lançamento instituído pela Resolução CONAMA n430 de 2011.

\section{CONSIDERAÇÕES FINAIS}

Os ensaios realizados mostraram o quão importante é de se realizar os ensaios com os coagulantes para encontrar as dosagens mais apropriadas para um melhor funcionamento do processo de coagulação/floculação. A presente pesquisa permitiu, para os coagulantes investigados, a 
determinação das condições operacionais ótimas ( $\mathrm{pH}$ e concentração de coagulante) em função da remoção de DQO (\%) e turbidez (\%) para o tratamento do efluente de frigorífico.

Dentre os três coagulantes investigados, o Tanino vegetal foi o que apresentou uma melhor eficiência dos resultados na remoção de turbidez $(99,75 \%)$. Para a remoção de DQO o coagulante que apresentou melhor remoção foi o Sulfato de Alumínio com $80,53 \%$.

Verifica-se também que $\mathrm{o} \mathrm{pH}$ reacional determinado como ótimo para $\mathrm{O}$ tratamento do efluente com o coagulante a base de tanino $(6,12)$, foi próximo ao $\mathrm{pH}$ do próprio efluente $(6,4)$, enquanto que para os demais coagulantes (PAC e sulfato de alumínio) $\mathrm{o} \mathrm{pH}$ reacional determinado foi mais distante do $\mathrm{pH}$ do efluente, fato que resultaria para esses coagulantes em um maior custo para ajuste do $\mathrm{pH}$ reacional no tratamento e também após a coagulação para adequá-lo ao requerido pela legislação para lançamento em um corpo receptor d'água (Resolução CONAMA N 430 de 2011), se for o caso.

Portanto, com o presente estudo concluiu-se que o coagulante Tanino apresentou-se como uma alternativa eficiente e promissora para o tratamento de efluentes de frigorífico, com uma vantagem adicional de ser um agente natural que minimiza os impactos ambientais uma vez que o efluente tratado e o lodo gerado não possuem traços de materiais inorgânicos causadores, com o acúmulo, em danos irreparáveis ao meio ambiente.

\section{REFERÊNCIAS}

AMERICAN PUBLIC HEALTH ASSOCIATION. Standard Methods for The Examination of Water \& Wastewater. $21^{\text {st }}$ ed. Washington: APHA, 2005.

BRASIL. Resolução CONAMA n $\mathbf{4 3 0}$, de 13 de maio de 2011. Padrões de lançamento de efluentes, 2011.
BRANCO, G. K.; ZORZIN, L. Tratamento de Efluente de Matadouro e Frigorífico de Suínos por meio de Coagulante Orgânico. 2016. TCC (Graduação em Tecnologia em Gestão Ambiental) -Universidade Tecnológica Federal do Paraná - UTFPR, Departamento Acadêmico de Ciências Biológicas e Ambiental. Medianeira, 2016.

CHOY, S. Y., PRASAD, K. M. N., WU, T. Y., RAGHUNANDAN, M. E., RAMANAN, R. N. Utilization of plant-based natural coagulants as future alternatives towards sustainable water clarification. J. Environ. Sci. (China), v. 26, p. 2178-2189, 2014. https://doi.org/10.1016/i.jes.2014.09.024

CHOY, S. Y., PRASAD, K. M. N., WU, T. Y., RAMANAN, R. N. A review on common vegetables and legumes as promising plantbased natural coagulants in water clarification. Int. J. Environ. Sci. Technol., v. 12, p. 367-390, 2015. https://doi.org/10.1007/s13762-013-0446-2

COSTA, J. D. Uso do coagulante orgânico tanino no tratamento de efluente de abatedouro avícola. 2016. Trabalho de Conclusão de Curso. (Graduação) Universidade Federal do Paraná, Palotina, 2016.

FERRARI, C. T. R. R.Uso de coagulantes naturais no tratamento de efluente da indústria de alimentos. 2015. Dissertação (Mestrado em Tecnologia de Alimentos) Universidade Tecnológica Federal do Paraná, Medianeira, 2015.

GOMES, B. M. F. Pré-Tratamento físicoquímico de efluentes industriais de um abatedouro de bovinos. Trabalho de Conclusão de Curso (Graduação em Engenharia Ambiental) -Universidade de Passo Fundo, Passo Fundo, RS, 2010.

MOHD-SALLEH, S. N. A., MOHD-ZIN, N. S., OTHMAN, N. A review of wastewater treatment using natural material and its 
potential as aid and composite coagulant. Sains Malaysiana, v. 48, p. 155-164, 2019. https://doi.org/10.17576/jsm-2019-4801-18

NAIME, R.; GARCIA, A.C. Utilização de Enraizadas no Tratamento de Efluentes Agroindustriais. Estudos tecnológicos, v. 1, n. 2, p. 9-20,- jul./dez., 2005.

OLADOJA, N. A. Headway on natural polymeric coagulants in water and wastewater treatment operations. J. Water Process Eng., v. 6, p. 174-192, 2015. https://doi.org/10.1016/j.jwpe.2015.04.004

ORSSATTO, F.; SILVA, F. M.; BRANCO, G. R. K.; ZORZIN, L.; FRARE, L. M. Tratamento de efluente de matadouro e frigorífico de suínos por meio de coagulante orgânico. In: CONGRESSO INTERAMERICANO DE ENGENHARIA SANITÁRIA E AMBIENTAL. 27., 2018. Foz do Iguaçu. Anais [...]. Foz do Iguaçu, 2018.

RODRIGUES, M. F. Avaliação da eficiência de coagulantes e floculantes na remoção de fósforo em efluentes de frigorífico de suínos. 2016. Trabalho de Conclusão de Curso (Graduação em Engenharia Ambiental e Sanitária)- Universidade Federal de Pelotas. Pelotas,RS, 2016.

ROSA, M. S. Avaliação do Emprego de Coagulantes Orgânico e Inorgânico no Tratamento Primário de Efluente de Abate e Industrialização de Aves. 2019. TCC (Graduação em Engenheiro Ambiental) Universidade Tecnológica Federal do Paraná. Medianeira, 2019.

SALEEM, M., BACHMANN, R. T. A contemporary review on plant-based coagulants for applications in water treatment. J. Ind. Eng. Chem., v. 72, p. 281297. 2019a. https://doi.org/10.1016/i.jiec.2018.12.029 coagulants for applications in water treatment. J. Ind. Eng. Chem., v.72, p. 281297, $2019 b$. https://doi.org/10.1016/j.jiec.2018.12.029

VIDAL, G.; CARVALHO, A.; MÉNDEZ, R.; LEMA, J. M. Influence of the content in fats and proteins on the anaerobic biodegradability of dairy wastewater. Bioresource Technology, v. 74, p. $231-239,2000$. https://doi.org/10.1016/S09608524(00)00015-8

VILLASEÑOR-BASULTO, D. L.; ASTUDILLOSÁNCHEZ, P. D.; DEL REAL-OLVERA, J.; BANDALA, E. R. Wastewater treatment using Moringa oleifera Lam seeds: A review. J. Water Process Eng., v. 23, p. 151-164, 2018. https://doi.org/10.1016/j.jwpe.2018.03.017

WEI, H., GAO, B., REN, J., LI, A., YANG, H. Coagulation/flocculation in dewatering of sludge: A review. Water Res., v. 143, p. 608631, 2018.

https://doi.org/10.1016/i.watres.2018.07.02 $\underline{9}$

WERBERICH, T. Diferentes tipos de coagulantes no tratamento de efluente de frigorífico. 2017. TCC (Graduação em Engenharia Agrícola e Ambiental) Universidade Federal do Mato Grosso, Instituto de Ciências Agrárias e Ambientais, Sinop, 2017.

YIN, C.Y. Emerging usage of plant-based coagulants for water and wastewater treatment. Process Biochem., v. 45, p. 14371444, 2010. https://doi.org/10.1016/i.procbio.2010.05.03 0

$\begin{array}{lll}\text { SALEEM, M.; } & \text { BACHMANN, } & \text { R. T. A } \\ \text { contemporary review on plant-based }\end{array}$

